UDC 631.461(479.24)

LBC 40.325.1(5A3e)

\title{
MICROBIOLOGICAL INDICATORS OF MEADOW-BROWN SOILS OF NATURAL CENOSES
}

\author{
Vafa Telman kyzy Mamedzade \\ Institute of Soil Science and Agro Chemistry of Azerbaijan National Academy of Sciences, Baku, Azerbaijan
}

\begin{abstract}
The article presents data on microbiological indicators of meadow-brown soils of semi-humid subtropics of the Lenkoran region. Meadow-brown soils are typical representatives of a number of hydromorphic soils of Azerbaijan. These soils are formed under sparse forests and shrub plantations with well-developed herbage. The soil-forming rocks are deluvial-proluvial deposits of clay composition. The influence of groundwater and surface runoff on soil formation is periodic. In the described soils, biological processes, including the activity of microorganisms, take place at moderate moisture level $(10-25 \%)$ and temperature $\left(18-23{ }^{\circ} \mathrm{C}\right)$. The paper presents a comparative analysis of the total number of microorganisms (in a layer of $0-50 \mathrm{~cm}$ ) between typical meadow-brown, meadow-brown leached, meadow-gray-brown and gray-earth-meadow soils. We have shown changes in the total amount of microbiota for individual horizons of meadow-brown soils. Changes in the quantitative indicators of the microbiota of the studied soils also affect their overall biogenicity. A close relationship has been established between humus and the number of microorganisms. As the humus decreases in individual horizons, an adequate decrease in the number of microbiota is noted. If in $0-5 \mathrm{~cm}, 5-10 \mathrm{~cm}, 10-15 \mathrm{~cm}$ layers the amount of microbiota varied between 6,13-5,83-4,81 million per gram of soil, then in deeper layers of $15-20 \mathrm{~cm}, 20-25 \mathrm{~cm}, 30-40 \mathrm{~cm}, 35-$ $50 \mathrm{~cm}$, their number gradually decreases to $3,9-3,10-2,65-1,81-1,52$ million per gram of soil.
\end{abstract}

Key words: soil, microorganisms, humus, biogenicity, groups of microbiota.

Citation. Mamedzade V.T. kyzy. Microbiological Indicators of Meadow-Brown Soils of Natural Cenoses. Prirodnye sistemy i resursy [Natural Systems and Resources], 2021, vol. 11, no. 3, pp. 34-38. DOI: https:// doi.org/10.15688/nsr.jvolsu.2021.3.5

УДК 631.461(479.24)

ББК 40.325.1(5Азе)

\section{МИКРОБИОЛОГИЧЕСКИЕ ПОКАЗАТЕЛИ ЛУГОВО-КОРИЧНЕВЫХ ПОЧВ ЕСТЕСТВЕННЫХ ЦЕНОЗОВ}

\author{
Вафа Тельман кызы Мамедзаде \\ Институт почвоведения и агрохимии НАНА, г. Баку, Азербайджан
}

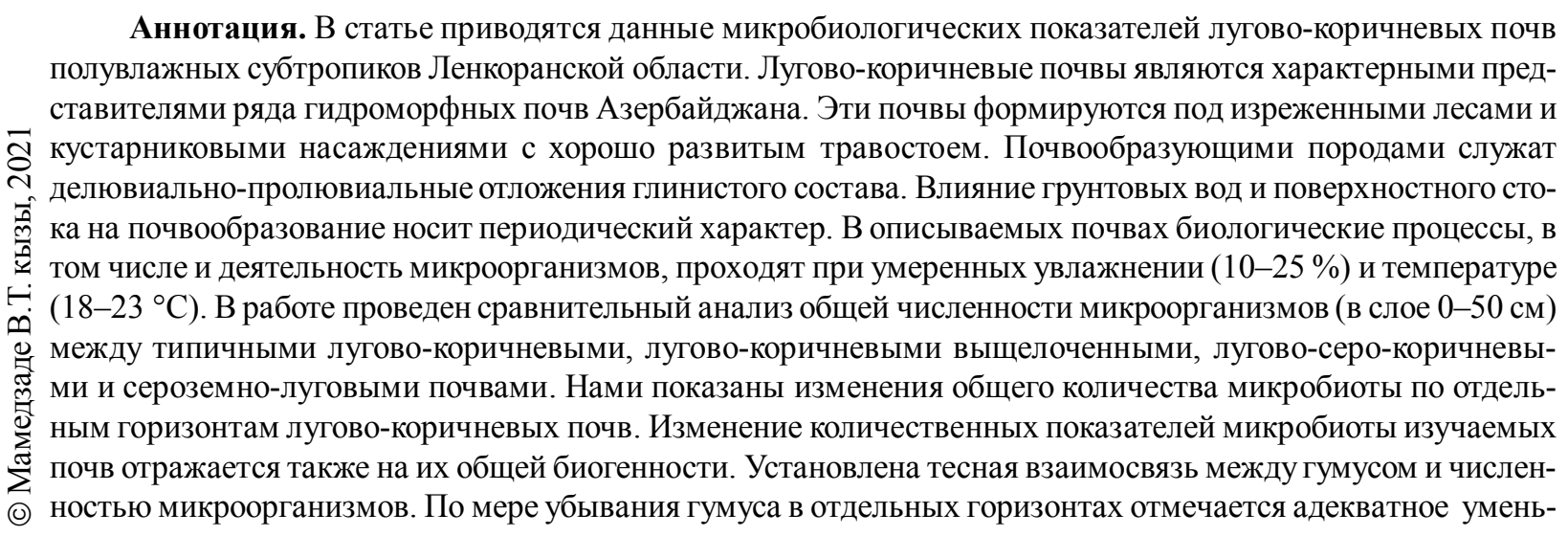


шение численности микробиоты. Так, если в слоях 0-5 см, 5-10 см, 10-15 см количество микробиоты варьировала между 6, 13-5,83-4,81 млн/г почвы, то в более глубоких слоях - 15-20 см, 20-25 см, 30-40 см, 3550 см - их численность постепенно уменьшается до 3,9-3,10-2,65-1,81-1,52 млн/г почвы.

Ключевые слова: почва, микроорганизмы, гумус, биогенность, группы микробиоты.

Цитирование. Мамедзаде В. Т. кызы. Микробиологические показатели лугово-коричневых почв естественных ценозов // Природные системы и ресурсы. - 2021. - Т. 11, № 3. - C. 34-38. - DOI: https:// doi.org/10.15688/nsr.jvolsu.2021.3.5

\section{Введение}

Микроорганизмы являются неотъемлемой составной частью природных биогеоценозов. В почвах различных регионов количество и групповой состав микроорганизмов качественно отличаются между собой, и поэтому для них характерны значительные ареалы распространения.

Проведенные микробиологические исследования в почвах, развивающихся в различных экологических условиях, показали, что микроорганизмы обладают характерными адаптивными механизмами, позволяющими им приспосабливаться к контрастным условиям окружающей среды [1-3; 6].

Микроорганизмы являются хорошим материалом для биотестирования почв, позволяющим проводить биологический контроль за состоянием окружающей среды, то есть комплексно осуществлять биомониторинг изучаемых почв.

Биотестирование почв целесообразно проводить не только в естественных и окультуренных ценозах, но и в техногенно-загрязненных биотопах $[6 ; 7 ; 9]$.

Микроорганизмы обладают большой физиологической активностью, благодаря которой они участвуют в различных биохимических процессах и превращении органических и минеральных компонентов почвы с образованием органоминеральных комплексов.

Целью работы стало выяснение существующей взаимосвязи между численностью микроорганизмов и органическим веществом почвы за счет изучения изменения количественных показателей микробиоты с общим содержанием гумуса в различных типах луговых почв.

\section{Объект и методика исследования}

Учитывая, что микроорганизмы в комплексе с другими представителями почвенной биоты принимают активное участие в почвообразовательном процессе, целесообразным было изучение микробиологического состояния лугово-коричневых почв, распространенных в Ленкоранской области.

Таким образом, основным объектом наших исследований были лугово-коричневые почвы (Джалилабад), которые формируются в условиях полувлажного - субтропического климата [4; 5].

Исследования проводились на выбранных естественных биотипах под хорошо развитым мезофильным травостоем. Микробиологические анализы на почвенных образцах, выбранных с отдельных горизонтов (0-10 см; $10-20 ; 20-30$ см) проводились по общепринятой в микробиологии методике с соблюдением всех мер асептики.

Для полной микробиологической характеристики различных типов луговых почв данного региона было проведено сопоставление и сравнительный анализ полученных результатов изучаемых почв, которые находятся на стадии лугового процесса почвообразования и испытывают влияние грунтовых вод.

\section{Результаты и их обсуждение}

Результаты микробиологических анализов показывают, что средняя численность микробиоты в 0-50 см слое лугово-коричневых типичных почв составляет 3829,19 тыс./Г почвы. При сравнении этих данных с микробиологическими показателями других типов луговых почв изучаемого региона было установлено, что в выщелоченных лугово-коричневых почвах, а также в лугово-серо-коричневых и сероземно-луговых почвах общая численность микроорганизмов изменяется между 3563,97-3474,07-2984,20 тыс./г почвы (см. табл. 1).

Как видно из этих данных, в рассмотренных почвах разница в количественных пока- 


\section{РЕСУ РСОВЕДЕНИЕ}

зателях сравнительно небольшая и составляет всего 1,07-1,10-1,28 раза.

На наш взгляд, такая близость полученных результатов связана с общим луговым процессом почвообразования - развитием луговой злаково-травянистой растительности и грунтовым увлажнением.

В связи с тем, что содержание гумуса в лугово-коричневой почве постепенно уменьшается по отдельным глубинам, адекватно изменяется и общая численность микроорганизмов.

Так, если в $0-50 \mathrm{~cm} ; 5-10$ см и $10-15$ см слоях почвы численность микробиоты варьируется между 6,13-5,83-4,81 млн/г почвы, то в более глубоких слоях (15-20 см; 20-25 см; 30-40 см; 35-50 см) их численность постепенно уменьшается до 3,90-3,10-2,65-1,811,52 млн/г почвы (см. рисунок).
Поскольку гумус и другие гумифицированные органические остатки являются основным энергетическим ресурсом для микроорганизмов, большую значимость представляет определение общей биогенности некоторых луговых почв (см. табл. 2).

В известной степени полученные данные могут служить показателями энергии превращения гумуса, или потенциальной биогенности почв.

Расчеты показали, что наибольшую биогенность имеют типичные лугово-коричневые и выщелоченные лугово-коричневые почвы, в которых общая биогенность изменяется между 203079,81-201733,20 тыс./г гумуса.

В лугово-серо-коричневых и сероземнолуговых почвах общая биогенность уменьшается соответственно до $180089.63-$ 118439,50 тыс./г гумуса.

Таблица 1

\section{Количественные показатели микроорганизмов в некоторых луговых почвах}

\begin{tabular}{|l|c|}
\hline \multicolumn{1}{|c|}{ Почвы } & $\begin{array}{c}\text { Численность микроорганизмов тыс./г почвы } \\
(0-50 \text { см слой })\end{array}$ \\
\hline Лугово-коричневая (типичная) & 3829,19 \\
\hline Лугово-коричневая (выщелоченная) & 3563,97 \\
\hline Лугово-серо-коричневая & 3474,07 \\
\hline Сероземно-луговая & 2984,20 \\
\hline
\end{tabular}

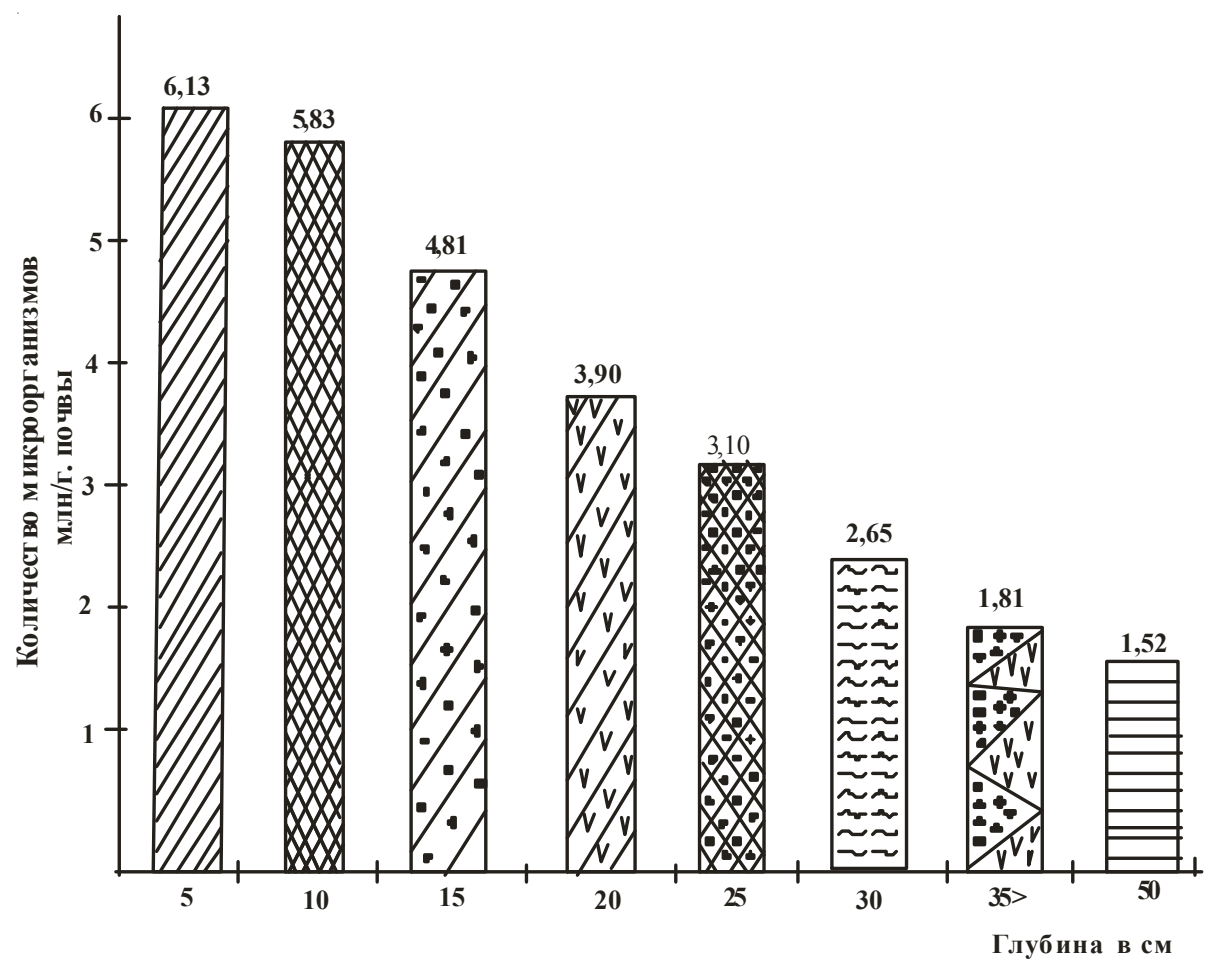

Динамика изменения количества микроорганизмов по глубинам лугово-коричневой почвы 
B.T. кызы Мамедзаде. Микробиологические показатели лугово-коричневых почв естественных ценозов

Таблица 2

Биогенность некоторых луговых почв (в пересчете на гумус)

\begin{tabular}{|l|c|}
\hline \multicolumn{1}{|c|}{ Почвы } & $\begin{array}{c}\text { Общая биогенность почв } \\
(0-50 \text { см слой }) \text { тыс./г гумуса }\end{array}$ \\
\hline Лугово-коричневая (типичная) & 203079,81 \\
\hline Лугово-коричневая (выщелоченная) & 201733,20 \\
\hline Лугово-серо-коричневая & 180089,63 \\
\hline Сероземно-луговая & 118439,50 \\
\hline
\end{tabular}

Примечание. Составлено по: [4; 6].

Микроорганизмы совместно с почвенными сапрофагами играют решающую роль в разложении и гумификации органических остатков, то есть сапрофитные группы микроорганизмов и беспозвоночные животные являются основными гумусообразователями в почве [8]. Исследование взаимосвязи микроорганизмов с количественными показателями гумуса проводилось на примере различных типов почв, как на естественных, так и на окультуренных ценозах $[1 ; 3]$.

Учитывая, что гумус является энергетически емким веществом, микроорганизмы, потребляя его, активно участвуют также в превращении гумусовых соединений. Однако последние разлагаются медленно, что связано с циклическим строением их молекул и способностью микроорганизмов отщеплять только боковые цепи $[1 ; 2 ; 6]$.

Сопоставляя полученные нами результаты по биогенности луговых почв с данными, приведенными в литературных источниках [1], мы находим между ними достаточную близость, что указывает на правильность проводимых исследований.

\section{Выводы}

1. Установлено, что средняя численность микроорганизмов в $0-50$ см слоя соответственно изменяется для лугово-коричневых (типичных), лугово-коричневых (выщелоченных), лугово-серо-коричневых и сероземнолуговых почв между 3829, 19-3568,973474,07-2984,20 тыс./Г почвы.

2. Общее количество микроорганизмов по глубинам лугово-коричневой почвы изменяется между 6,13-3,9-1,52 млн/г почвы.

3. Биогенность некоторых луговых почв составила соответственно 203079,81 тыс./г гу- муса; 201733,20 тыс./Г гумуса 180089,63 тыс./Г гумуса и 118439,50 тыс./г гумуса.

\section{СПИСОК ЛИТЕРАТУРЫ}

1. Алиева, Б. Б. Взаимосвязь между микробиологическими показателями и сооружением гумуса в горнолесных бурых почвах / Б. Б. Алиева, В. Т. Мамедзаде // Труды общества почвоведов Азербайджана. - 2019. - T. XV. - С. 121-127.

2. Гасымова, Г. С. Почвенная микробиология / Г. С. Гасымова. - Баку: Изд-во БГУ, 2008. - 205 с.

3. Мамедзаде, В. Т. Микробиологическая характеристика горно-лесных коричневых почв агроценозов под плодовыми культурами / В. Т. Мамедзаде // Труды общества почвоведов Азербайджана. $-2016 .-$ Т. 14. - С. 106-110.

4. Мамедова, С. 3. Экологическая оценка и мониторинг почв Ленкоранской области Азербайджана / С. 3. Мамедова. -Баку : Элм, 2006. - 36 с.

5. Морфогенетическая диагностика, номенклатура и систематика почв Азербайджана / М. П. Бабаев, В. Г. Гасанов, Ч. М. Джафарова, С. М. ГусейноваБаку : Элм, 2011.-448 c.

6. Напрасникова, Е. В. Эколого-микробиологическая и биохимическая характеристика почвенного покрова в условиях аэротехногенного загрязнения / Е. В. Напрасникова, Л. П. Макарова // Известия Иркутского государственного университета. Серия «Биология и Экология». - 2012. - Т. 5, № 2. - С. 19-26.

7. Переведенцева, Л. Г. Микология: грибы и грибоподобные организмы / Л. Г. Переведенцева. СПб. : Лань, 2012. -272 c.

8. Самедов, П. А. Влияние беспозвоночных животных на микробиологическую обстановку почв / П. А. Самедов // Труды Общества почвоведов Азербайджана. - Баку: Элм, 2005. - С. 204-210.

9. Crazes, I. M. Fluctuating asymmetry of the yellow meadow and along a metal-pollution gradient / I. M. Crazes, M. Okrutmak, P. Szpila // Pedobiologia. 2015. - Vol. 58, № 5. - P. 195-200. - DOI: https:// dx.doi.org/10.1016/j.pedobi.2015.11.001. 


\section{РЕСУ РСОВЕДЕНИЕ}

\section{REFERENCES}

1. Aliyeva B.B., Mamedzade V.T. Vzaimosvyaz' mezhdu mikrobiologicheskimi pokazatelyami i sooruzheniem gumusa $\mathrm{v}$ gornolesnykh burykh pochvakh [Correlation Between Microbiological Indices and Humus Construction in Mountainous Brown Soils]. Trudy obshchestva pochvovedov Azerbaydzhana [Proceedings of the Azerbaijan Society of Soil Scientists], 2019, vol. 15, pp. 121-127.

2. Gasymova G.S. Pochvennaya mikrobiologiya [Soil Microbiology]. Baku, Izd-vo BGU, 2008. 205 p.

3. Mamedzade V.T. Mikrobiologicheskaya kharakteristika gorno-lesnykh korichnevykh pochv agrotsenozov pod plodovymi kul'turami [Microbiological Characteristics of Mountain Forest Brown Soils of Agrocenosis Under Fruit Crops]. Trudy obshchestva pochvovedov Azerbaydzhana [Proceedings of the Azerbaijan Society of Soil Scientists], 2016, vol. 14, pp. 106-110.

4. Mamedova S.Z. Ekologicheskaya otsenka $i$ monitoring pochv Lenkoranskoy oblasti Azerbaydzhana [Ecological Assessment and Monitoring of Soils in Lenkoran Region of Azerbaijan]. Baku, Elm Publ., 2006. 36 p.

5. Babayev M.P., Gasanov V.G., Dzhafarova Ch.M., Guseynova S.M. Morfogeneticheskaya diagnostika, nomenklatura i sistematika pochv Azerbaydzhana
[Morphogenetic Diagnosis, Nomenclature and Systematics of Azerbaijan Soils]. Baku, Elm Publ., 2011. $448 \mathrm{p}$.

6. Naprasnikova Ye.V., Makarova L.P. Ekologomikrobiologicheskaya i biokhimicheskaya kharakteristika pochvennogo pokrova $\mathrm{v}$ usloviyakh aerotekhnogennogo zagryazneniya [EcoMicrobiological and Biochemical Characteristics of Soil Cover Under Conditions of Airborne Technogenic Pollution]. Izvestiya Irkutskogo gosudarstvennogo universiteta. Seriya «Biologiya i ekologiya» [The Bulletin of Irkutsk State University. Series "Biology. Ecology"], 2012, vol. 5, no. 2, pp.19-26.

7. Perevedentseva L.G. Mikologiya: griby $i$ gribopodobnye organizmy [Mycology: Fungi and Fungus-Like Organisms]. Saint Petersburg, Lan Publ., 2012.272p.

8. Samedov P.A. Vliyanie bespozvonochnykh zhivotnykh na mikrobiologicheskuyu obstanovku pochv [Influence of Invertebrates on the Microbiological Environment of Soils]. Trudy Obshchestva pochvovedov Azerbaydzhana [Proceedings of the Azerbaijan Society of Soil Scientists]. Baku, Elm Publ., 2005. pp. 204-210.

9. Crazes I.M., Okrutmak M., Szpila P. Fluctuating Asymmetry of the Yellow Meadow and Along a Metal-Pollution Gradient. Pedobiologia, 2015, vol. 58, no. 5, pp. 195-200. DOI: https://dx.doi.org/ 10.1016/j.pedobi.2015.11.001.

\section{Information About the Author}

Vafa Telman kyzy Mamedzade, Doctor of Philosophy in Biological Sciences, Senior Researcher, Laboratory of Soils Biology, Institute of Soil Science and Agro Chemistry of Azerbaijan National Academy of Sciences, M. Ragima St, 5, AZ10073 Baku, Azerbaijan, vefamemmedzade@gmail.com

\section{Информация об авторе}

Вафа Тельман кызы Мамедзаде, доктор философии по биологическим наукам, старший научный сотрудник лаборатории почвенной биологии почв, Институт почвоведения и агрохимии НАНА, ул. М. Рагима, 5, AZ10073 г. Баку, Азербайджан, vefamemmedzade@gmail.com 